JPE 12-5-17

\title{
Power Electronics Open-Source Educational Platform
}

\author{
Ana Pozo-Ruz ${ }^{\dagger}$, F. David Trujillo Aguilera*, M. José Morón*, and Ernesto Rivas* \\ ${ }^{\dagger}$ ETS Ingeniería Industrial, University of Málaga, Málaga, Spain \\ *Escuela Politécnica Superior, University of Málaga, Málaga, Spain
}

\begin{abstract}
Learning Power Electronics is essential in both electrical and electronic engineering fields and the introductory courses are similar in many universities. Taking this premise into account, an educational computer-aided platform for power electronics will be presented in this paper. This educational platform includes an e-book, a set of power electronics animations, Java simulations, as well as several hands-on training sessions. The main advantages of this platform are twofold. First, all necessary teaching tools are combined on a single platform. And secondly, access to this platform is available free of charge and with no complicated registration requirements. In addition to traditional teaching techniques, the use of this platform has demonstrated an increase in student participation and has consistently improved their academic performance. Data consist of surveys, which guarantee both reliability and validity through psychometric techniques.
\end{abstract}

Key words: Computer aided platform, Engineering education, Interactive educational tool, Open access, Power electronics, Power electronics laboratory, Power electronics simulation

\section{INTRODUCTION}

Power electronics is a discipline that encompasses a wide range of real-life applications in industrial, commercial and residential environments [1]. Therefore, the learning of this discipline in electronic engineering is essential. In this sense, an increased interest in providing power electronics subjects both at the senior undergraduate and graduate levels in various universities and institutions has been awakened [2].

Additionally, in the last decades, power electronics has gone through intense development in many aspects of technology, including power devices, control methods, circuit design, computer-aided analysis, etc [3]-[5]. This development has brought about an increase of the content to be taught in power electronics. In this context, Mohan and his colleagues at the University of Minnesota have reorganized the traditional power electronics courses so that students, in a first course, learn the basic principles of operation of power electronics converters, devices control and utility applications [6]. In subsequent

Manuscript received Sep. 21, 2011; revised Jul. 20, 2012

Recommended for publication by Associate Editor Se-Kyo Chung.

${ }^{\dagger}$ Corresponding Author: apozo@uma.es

Tel: +34-951-952-465, University of Málaga

Escuela Politécnica Superior, University of Málaga, Spain courses, areas such as digital signal processing applications, programmable logic and digital control should be covered [7].

In fact, most curricula in formal university engineering education only consider a first general course or subject in power electronics, and leave aspects such as research and development oriented to real industrial applications for more advanced or even postgraduate courses.

In this sense, the content of this introductory course relative to power electronics is similar in many universities, and covers the different converter topologies, their control and some design aspects and applications. Therefore, books and tools used for teaching can be employed as support material independently of the university. This is the case, for example, the power electronics books written by Mohan et al. [8], Rashid [9], Kassakian [10], Hart [11], Bose [12], etc., that are extensively used as text books at universities throughout the world.

In this framework, the authors have developed an educational computer-aided platform for power electronics that can be used as on-line teaching tool both for any first year course and for any general purpose course in power electronics.

The platform takes advantages of the potential of Internet and multimedia tools for educational purposes, such as interactivity, dynamism, accessibility any place or any time. 
The benefits of this computer-aided on-line platform for power electronics are:

- It combines, in a single platform, all tools needed for a power electronics course: a complete e-book, power electronics animations, Java simulations and power electronics laboratory tutorial. This is significant due to the infinite number of on-line resources and information related to power electronics on the Web that could confuse and overwhelm students.

- It is an open access platform, that is, it is freely available on Internet, and it can be used by any student or teacher without charge, registration or password.

- It allows students to interact with the tool and organize their learning process.

- It is very useful for any student of this discipline as it covers all the basic aspects of power electronics, with an extensive content.

Conversely, as a drawback, it is worth mentioning that an excessive employment of e-learning methods, based on new informatics technologies could imply a lack of reasoning process. Consequently, b-learning methods, instead of pure e-learning, have been employed in the methodology described in this paper. Therefore, this paper describes this educational computer-aided platform for teaching power electronics, as well as its applications, in an initial course of this subject. In particular, this platform has been conceived as an aid in learning for undergraduate students. As case of study, the "Power Electronics System" subject, belongs to the ETS Ingeniería Industrial of the University of Málaga, has been considered.

This paper is structured as follows. Section II presents the necessity of new tools for power electronics teaching. Subsequently, section III describes in detail the developed computer-aided platform for power electronics. Later, section IV focuses on how the integration of this tool, as aid and support for traditional learning techniques, has contributed to improve the student grades in power electronics subject. Finally, section $\mathrm{V}$ summarizes the main conclusions of this project.

\section{NECESSITY OF NEW TOOLS FOR TEACHING POWER ELECTRONICS}

The main goal of a first year course in power electronics is to learn the basic principles of operation of power electronics converters and control devices, as well as to provide the students a brief introduction to the main power electronics applications. One of the major difficulties in power electronics lies with the nonlinearity and mathematical complexity of power electronics circuits, which greatly complicates its theoretical analysis. Therefore, it is necessary to use appropriate teaching techniques to improve students' understanding of these challenging concepts.

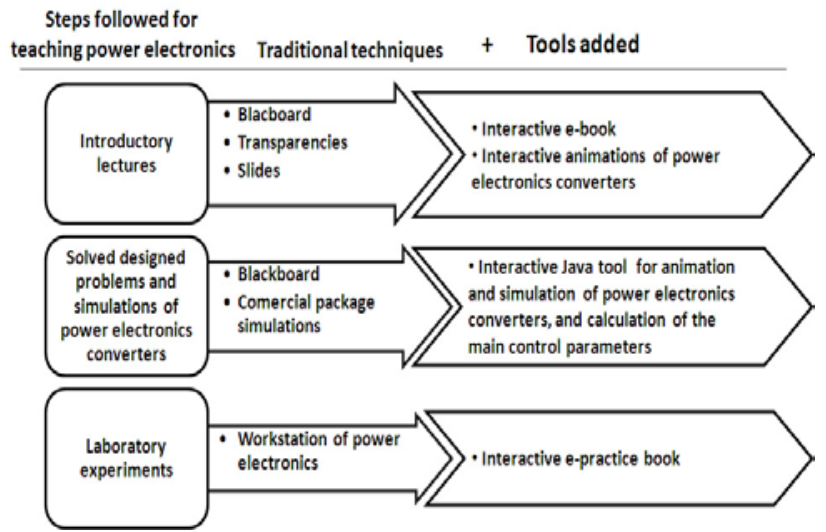

Fig. 1. Step and techniques for power electronics teaching.

The traditional method for teaching power electronics focuses on lectures, using resources such as text books, blackboard or slides. This methodology has the advantage of allowing the teacher to present the contents to a wide audience. However, it presents several drawbacks in the case of power electronics, such as: how to show the intervals in which each device is in the on/off state; how to illustrate the dynamic behavior of the system; and finally, how to demonstrate the complex waveforms of the currents for each interval [13]-[15]. Moreover, these kinds of resources are static, involving minimal interaction and thus they cannot exemplify the effects of changing the load and control parameters over the waveforms.

Thus, circuit simulation packages, such as PSpice, PSIM, MATLAB/SIMULINK, have become an essential tool in any power electronics course. The main reason is that these simulation packages are strongly recommended for complementary and advanced circuit analysis since they provide complex models with almost realistic behavior [16]. In addition, the hands-on training laboratory exercises improve students' skills knowledge [17], help students to assimilate the theoretical concepts as well as to facilitate a first contact with the instrumentation and equipment that in the professional future the students will work with [18].

In brief, for teaching a first course of power electronics, the steps followed and the tools traditionally employed are (Fig. 1): (a) introductory lectures: blackboard, slides and transparencies; (b) solving proposed problems: blackboard and simulations of the power electronics converters using commercial package simulations and, finally, (c) implementation of the studied converter, in a hardware laboratory, and comparison of the results obtained from the simulated ideal circuits with the real experiments.

These techniques and tools have been the ones used by authors until the academic year 2006-2007. However, students had still serious difficulties in understanding the subject, specifically in the analysis of switched power converters.

Therefore, it was necessary to develop other tools in conjunction with traditional techniques for power electronics 
teaching. With this combination, students can perform a comprehensive analysis of electrical circuits, as well as design and model power electronics circuits [19]- [22].

These new tools, based on multimedia and information technologies, are integrated as a single platform in a website, freely available on Internet. These tools are more useful for both students and instructors. In fact, teaching is more efficient because these tools allow numerous circuit states to be represented clarifying the dynamic behavior which is so difficult to illustrate with static slides.

Thus, the tools developed for each of the steps followed for teaching a first power electronics course are (Fig. 1):

1) Introductory lectures: interactive e-book version of the text book written by authors [23] that includes the study of power semiconductors, the different power electronics converter topologies as well as the main industrial applications and home power electronics applications. This e-book has been completed with interactive animations in Adobe Flash to study, in each period, the analytically control parameter values and graphical waveforms [24], [25]. Both online tools complement the traditional presentation techniques: blackboard, transparencies and slides.

2) Solving proposed problems and simulations of power electronics converters: profitable interactive web-based tool employing a free authoring tool written in Java, called EasyJava [26]. This tool generates an interactive visualization of simulation of a power electronics converter in the steady state in real time, with the parameters introduced by the student. The results shown during the simulation are the waveforms of output voltages and currents, the animation of the state of switches and the current circulation in each period and, finally, the calculation of some important control values such as commutation interval, main load voltage, etc. Therefore, this tool allows the students to solve the problems proposed and to check the results by themselves.

3) Laboratory experiments are performed in the workstations of power electronics that include basic laboratory equipment as well as a training station of power electronics. The instructions to implement the experiments and laboratory sessions are included in the interactive e-practice-book, a multimedia web tool created by authors free available on Internet [27].

The following section explains the developed educational platform for power electronics teaching. The educational platform includes the four basic power electronics converters (ac-ac, dc-ac, dc-dc and ac-dc), as well as an introduction of semiconductors and power electronics applications. In this paper, the explanation of the platform is focused on the ac-dc three-phase controlled converters, in the configurations of half bridge and full bridge, as they are the most challenging for students to understand. Nevertheless, in order to show the potential of the platform, additional figures corresponding to other topologies, such as dc-dc, will be added.

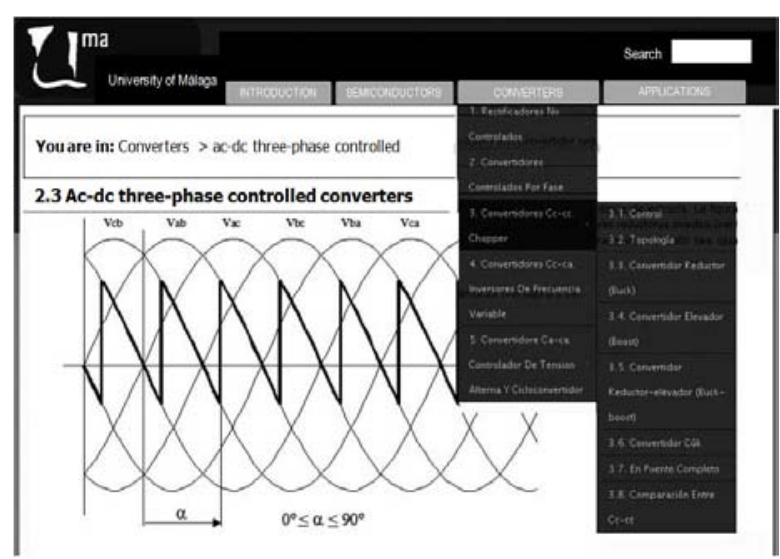

Fig. 2. Power electronics e-book.

\section{INTERACTIVE MULTIMEDIA TOOLS}

\section{A. E-book}

The objective of the power electronics e-book is to provide a free online textbook that allows students to find the topic to study readily. The e-book has been developed in a Windows environment using Joomla! [28], an open source application built on PHP (Hypertext Pre-Processor) under GNU (General Public License). The e-book is hosted on the server of the University of Málaga and its access is free through the url: www.uma.es/investigadores/grupos/electronica_potencia.

There are other many sites that provide complete books or selected chapters freely available on Internet to any interested user in power electronics. Such is the case of the Indian Institute of Technology Kharagpur [29], which offers a complete book of power electronics divided into different modules and each module in lessons. Each lesson consists of a PDF file that users can download freely. Another important initiative has been elaborated by the Massachusetts Institute of Technology (MIT) that created the OCW-MIT (Open Ware Course) in April 2001, where free educational materials are offered by teachers, as a study aid [30]. This initiative has spread to other universities. Thus, Carlos III University of Madrid (Spain) has a power electronics course developed in OCW. However, OCW consists of an index that links to files (videos, PDF, audio) or other external websites [31]. But both examples mentioned have static contents, consisting of a repository of files related to lessons, problems, slides, etc. The user cannot navigate through the book, and it has no interactive elements.

Thus, in the e-book implemented, at the top of the home page, a set of pull-down menus let students navigate easily through the main topics (Fig. 2). The content of the e-book is organized into four sections:

1) Introduction: an overview of power electronics.

2) Power semiconductors: diodes, BJT transistors, MOSFET transistors, thyristors, IGBTs, IGCTs, GTOs and triacs.

3) Power electronics converters:

a) ac-dc uncontrolled rectifiers: single-phase and 
three-phase.

b) ac-dc phase-controlled converters: single-phase and three-phase.

c) dc-dc converters: buck, boost, buck/boost, Cuk and dc-dc full-bridge converter.

d) dc-ac converters: single-phase and three-phase.

e) ac-ac converters: ac voltage controllers and cycloconverters.

4) Power electronics applications: dc power switched, uninterruptible power supplies and applications of power electronics systems.

The e-book also has the option to print each section of a lesson, save it in PDF format or send the content by email.

\section{B. Power Electronics Animations}

This tool is the complement to the power electronics e-book. In this tool, the performance principles of power electronics converters are explained and illustrated by means of videos and animations. These videos are implemented using Adobe Flash multimedia software [32], software designed for creating Web animations.

The videos are freely available at the following link: www.uma.es/investigadores/grupos/electronica_potencia/docu ments/tutoriales/web_convertidores_nuevo2/index.htm

By using the animations, students can analyze, step by step, the behavior of the selected power electronics converter. The displaying of this analysis is performed in two ways: analytically, showing the control parameter values; and graphically, through the waveforms.

A total of 24 videos, for the different topologies of switched power converters, have been implemented. Fig. 3 shows the ac-dc three-phase converter in full-bridge configuration with $R L V_{d}$ load operating in continuous mode and Fig. 4 shows a dc-dc boost or step-up converter.

Every video contains the following sections:

1) The heading, with the next information: the name of the power electronics converter, the control parameters and the analytical result of the converter in each state.

2) The electronic circuit animation of the power electronics converter.

3) A graphic screen where the resulting waveforms are displayed: input voltage and output voltage.

4) A control panel to regulate the animation: forward continuous mode, reverse continuous mode, forward step by step, reverse step by step, stop, go to the animation beginning and go to the animation end.

\section{Simulation on Java}

This tool allows the students to reproduce the animation and, for the exercises proposed, to obtain analytical results and waveforms which can be compared with their solutions. To run this tool, students only need an Internet connection and the Java virtual machine. The tool is freely available at the link: www.uma.es/investigadores/grupos/electronica_potencia/doc uments/tutoriales/easyjava/index.htm
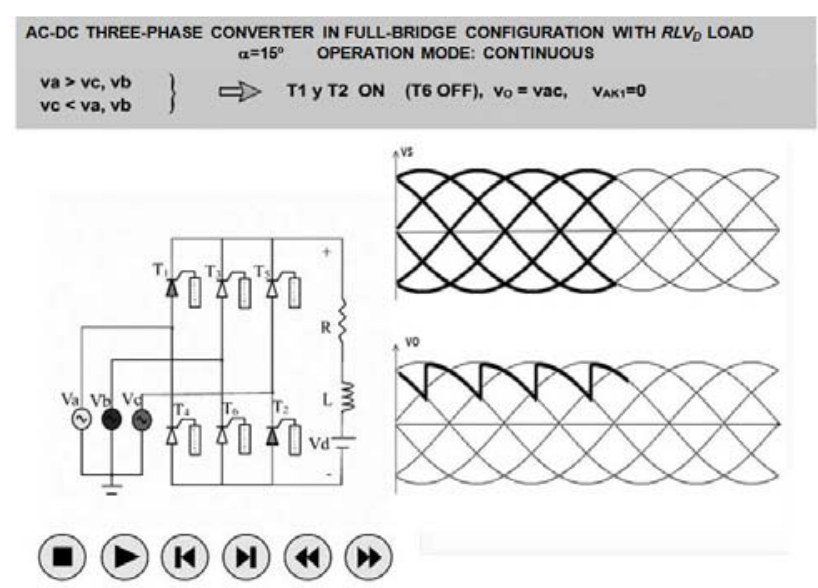

Fig. 3. Ac-dc three-phase converter in full-bridge configuration with $R L V_{d}$ load animation.

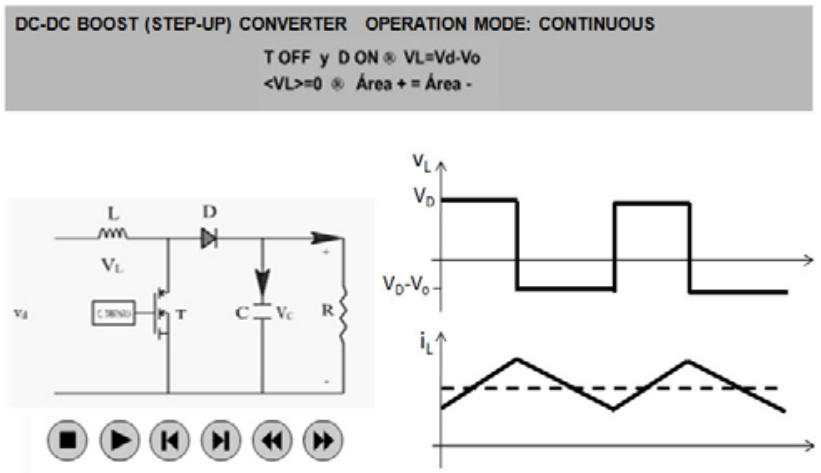

Fig. 4. Dc-dc step-up (boost) converter animation.

Despite the wide range of specific software focusing on the simulation of power electronics converters, such as PSIM [33], SABER [34], and others that can be applied to power electronics as MATLAB/SIMULINK [35] or PSpice [36], the authors have chosen to create a new specific tool for several reasons:

1) Circuit simulation packages require software installation tool; consequently, learning how to use the simulation tool before starting to study the desired topic is necessary. Furthermore, if the students do not know the key concepts of the circuit under analysis, students encounter difficulties designing and simulating the circuits with a professional simulator.

2) Circuit simulation package provide the graphical results of the simulation, but not the analytical results. So that, although the students can test the waveforms of their solution, it is not possible to get the numerical value of the required parameters such as firing angle $\alpha$ or commutation angle $u$.

For ac-dc three-phase controlled converters, Fig. 5 shows the main frame corresponding to the half-bridge topology and Fig. 6 displays the main frame for the full-bridge topology.

As it can be observed, both windows contain the electronic circuit schematic and, at the top, four tabs with the legends of the input parameters, load, waveforms and calculations. 


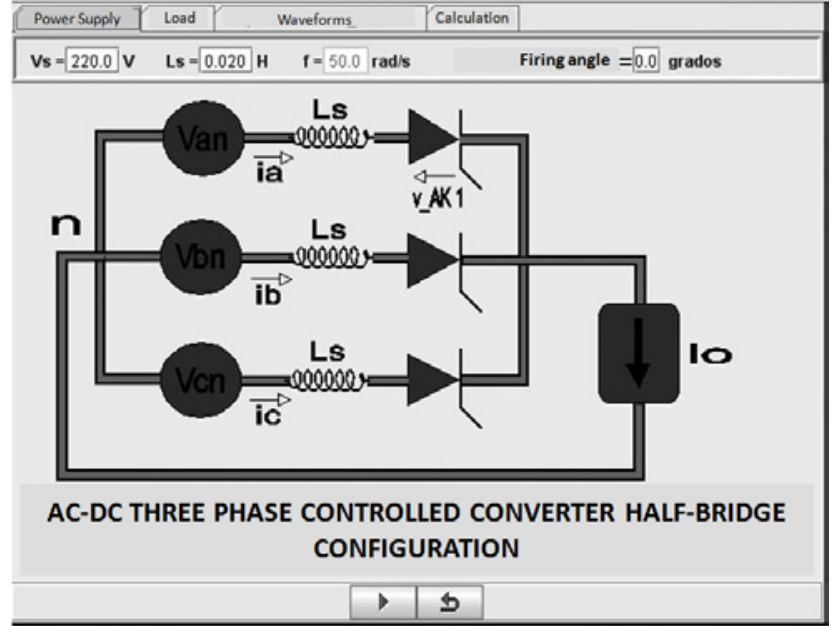

Fig. 5. Main frame of the Java tool, corresponding to the ac-dc three phase controlled converter half-bridge topology.

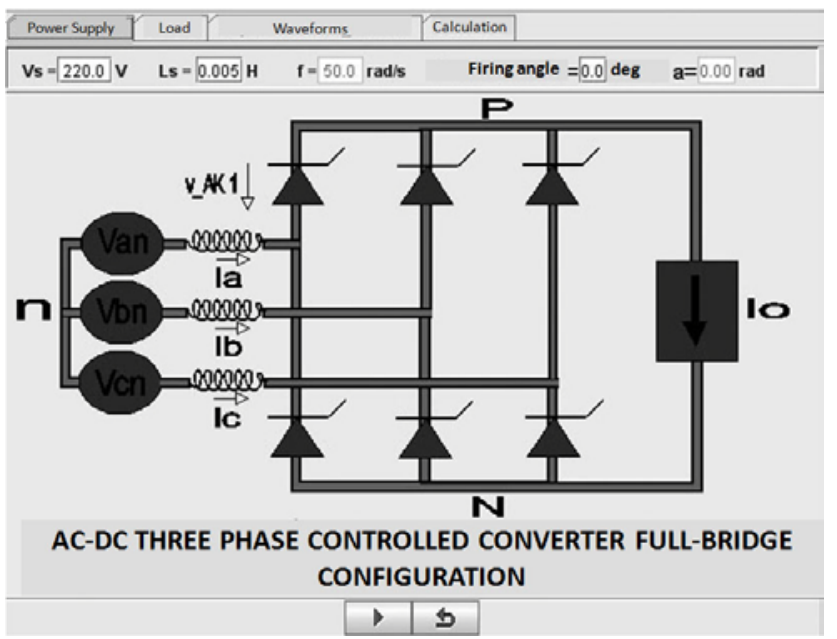

Fig. 6. Main frame of the Java tool, corresponding to the ac-dc three phase controlled converter full-bridge topology.

The first two tabs are active, that is, the student can introduce values to perform the desired analysis. As input parameters, students can set the rms value of the power supply, frequency, firing angle and commutation inductance. This is an inductance, called $L_{s}$, in serial with the three-phase input voltage that avoids thyristors turn on and turn off instantaneously. As load, it can be chosen any combination of $R, L$ and $V_{d}$ (emf, electromotive force), as well as their corresponding values.

The last two tabs are inactive. In the tab named "graphic representation", students select the waveforms to be shown simultaneously. These can correspond to output voltage, output current, drop voltage in the thyristors, and phase current, as it is shown at Fig. 7 for half-bridge topology and Fig. 8 for full-bridge topology. Finally, the tab "calculations" provides the results of the analytical operation. So, in case of ac-dc three-phase controlled, information provided is: the operation mode and the commutation angle $u$.

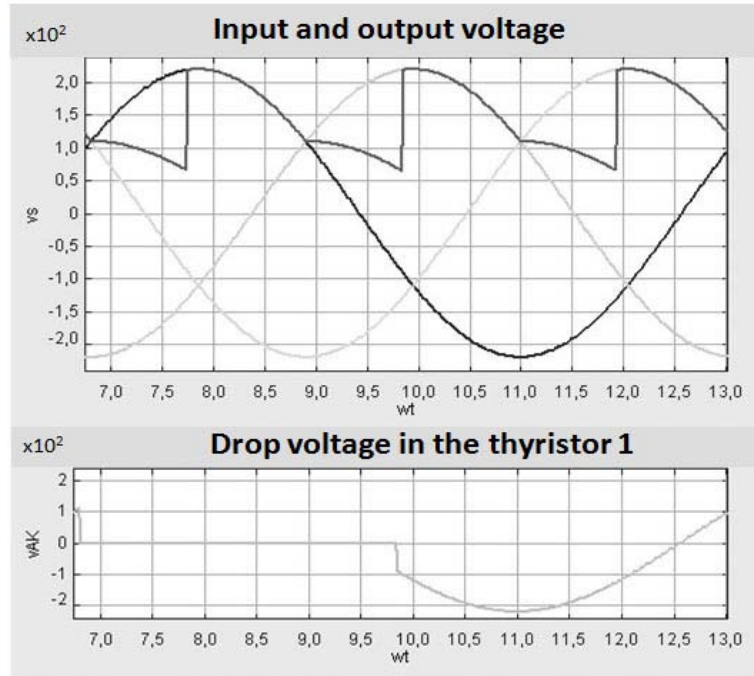

Fig. 7. Waveforms of the simulation of an ac-dc three-phase controlled converter half-bridge topology.

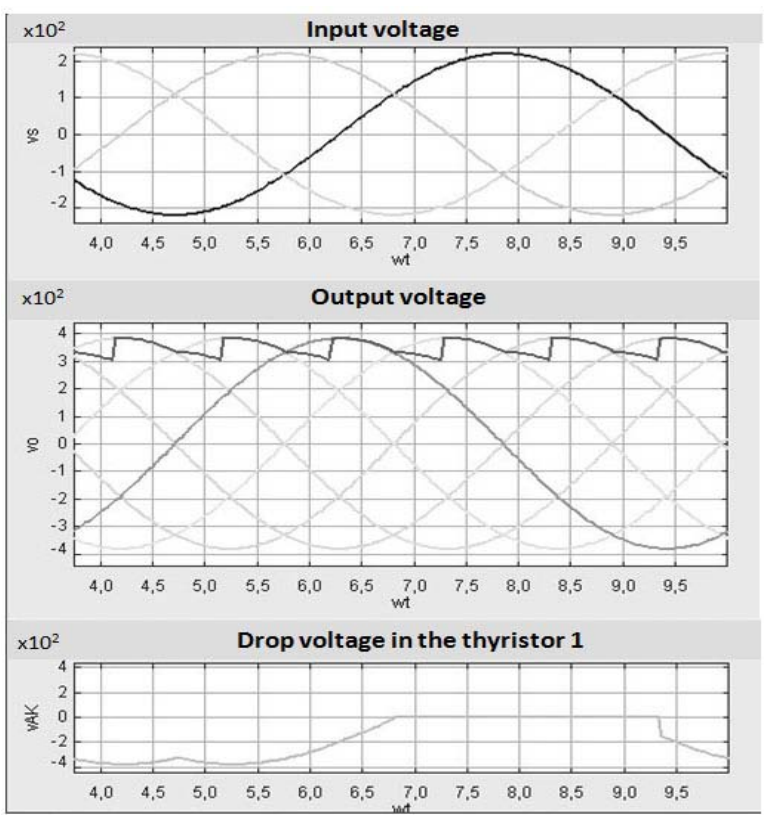

Fig. 8. Waveforms of the simulation of an ac-dc three-phase controlled converter full-bridge topology.

When students run the application, firstly they choose the power electronics converter to analyze. After fixing the input parameters indicated in the exercise, students select the waveforms to display and click the play button. Then, the circuit animation starts to work. While this animation is running, the selected waveforms are updated continuously.

So, students can observe and study the relation between the state of the circuit operation and its waveform at each instant. Animation ends at four periods. After that, by clicking the tab "calculations", students can check if their results calculated match with the ones provided by the simulation.

Similar results could be obtained with the rest of topologies implemented, such as dc-dc step-down or buck converter (Fig. 9 and Fig. 10). 


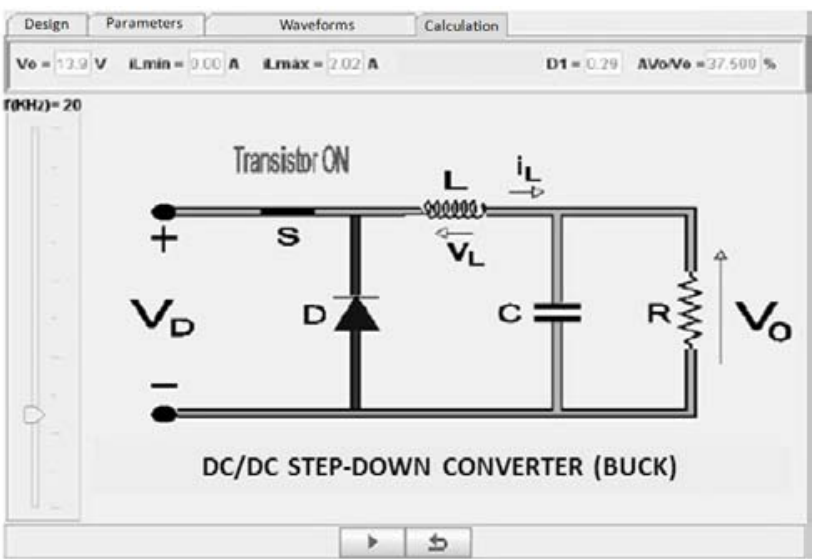

Fig. 9. Main frame of the Java tool, corresponding to the dc-dc step-down (buck) topology.

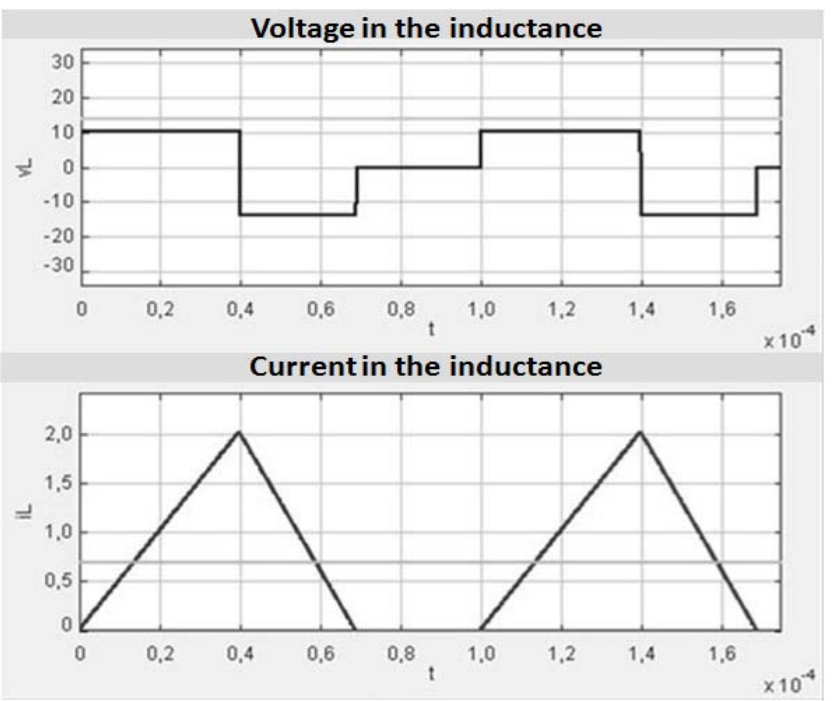

Fig. 10. Waveforms of the simulation of dc-dc step-down (buck) topology.

Other tools for simulation of power electronics converters in Java can be found in the web, such us Interactive Power Electronics Seminar (iPES) of the Zurich University [37], available in www.ipes.eth.ch. This tool has the inconvenience that the software employed, Gecko Circuits Research [38], requires the payment of a license. The University of Sao Paulo has developed an interesting power electronics tool in Java which integrates PSpice [39]. This tool is available in: www.dee.feis.unesp.br/docentes/flavio/lepjava/index.php.

However, while the possibilities of this software are similar to the tool presented in this paper, the Sao Paulo software does not include the commutation inductance effect in the ac-dc converters.

Another interactive Power Electronics online text can be found in http://services.eng.uts.edu.au/ venkat/pe_html /peintro.htm. The web provides MATLAB, C, PSpice and Java source files, however, it does not support the configuration of converters nor does it provide animations or numerical data. Additionally, it only includes several ac-dc converters.

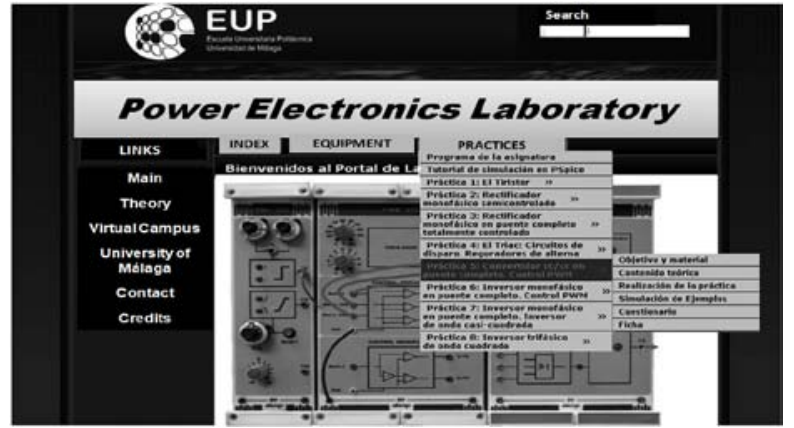

Fig. 11. E-practice book.

Therefore, the proposed platform offers more resources to directly observe problem resolution for better instruction.

\section{Laboratory}

Once students have studied, simulated, performed and validated the set of proposed exercises, they are able to implement these power electronics converters in the laboratory.

It is essential that students carry out hardware-based laboratory experiments. In fact, the practice of replacing hardware training by simulation tools is being adopted by many universities. Unfortunately, this is insufficient for proper instruction. Students need to manipulate real hardware -designing, implementing and testing hardware systems - in order to acquire the skills necessary for the real world.

The power electronics laboratory in the University of Málaga has five workstations. Each workstation includes the following instruments: digital oscilloscope, function generator, dc-ac power supply, three-phase connection, digital multimeter, differential voltage probe, clamp and power electronics training based on modules.

The power electronics training based on modules is a didactic commercial equipment composed of different interconnected elements, that allows the configuration of the different topologies of power electronics converters. Its philosophy is similar to that developed at the University of Minnesota [40].

The didactic equipment employed in the laboratory contains:

- A phase transformer 220/280-22/30 V ac.

- A pulse generator module.

- A module with power thyristors, to configure single-phase rectifiers and three-phase half-bridge and full-bridge topologies.

- Several loads: resistors, inductances, dc sources.

In order to provide a guide to aid in the proposed training sessions, an e-practice-book has been created. This e-practice-book has been developed in a Windows environment using Joomla! [28]. The e-practice-book is available in the link: www.uma.es/investigadores/grupos/electronica_potencia/labor atorio. Students have full access from the home page all the contents of the e-practice-book. Specifically, the pull-down menu called "practices" contains the following elements (Fig. 
11):

- Objectives and material used in each practice.

- Theoretical analysis, where a clear and simple theory for the correct understanding of each practice is presented.

- A sample implementation, that includes animations of each of the assemblies in order to guide to students, step by step, in each practice performance.

- Self-assessment questionnaires that are sent automatically to the teacher by email. Also, if it was necessary, students could even send graphics files with screenshots from the oscilloscope.

Once the training sessions have been implemented, students can establish a comparison between experimental results and simulation results using the tool proposed. As an example, Fig. 12 draws the results, for an ac-dc three-phase controlled converter in a half-bridge topology in the continuous mode and RL load, from oscilloscope and simulation.

\section{OBTAINED RESUlts}

In order to measure the quality and the performance of the platform explained in this paper, awareness of students' point of view is essential. The authors have collected subjective data through satisfaction surveys and objective data through mark statistics [41]. The satisfaction surveys have guaranteed its reliability and validity by means of psychometric techniques.

As case of study, authors have considered the "Power Electronics System” subject, a basic power electronics undergraduate subject belonging to the fourth course of the E.T.S. Ingeniería Industrial of the University of Málaga.

This subject consists of 60 hours, distributed in 4 hours per week, over 15 weeks. Over these 60 hours, the authors have performed the steps explained for power electronics teaching as well as the combination of traditional techniques and interactive multimedia tools implemented.

These interactive multimedia tools have been gradually introduced in the past courses. That is, in 2007/2008 course, the students used the free online e-book, and the e-practice-book. Moreover, the power electronics animations were implemented along 2008/2009 course. And finally, in the course 2009/2010, and subsequent courses, the students could work with facilities of the Java Simulations. In Table I, the mark statics are drawn [42]. It represents three ratios: D/R,

TABLE I

Historical DATA OF THE POWER ELECTRONICS SYSTEM SUBJECT: R: REGISTERED, D: DONE, P: PASSED

\begin{tabular}{|c|c|c|c|c|c|c|}
\hline $\begin{array}{c}\text { ACADEMIC } \\
\text { YEAR }\end{array}$ & $\mathbf{R}$ & $\mathbf{D}$ & $\mathbf{P}$ & $\mathbf{\% D} / \mathbf{R}$ & $\mathbf{\% P} / \mathbf{R}$ & $\mathbf{\% P / D}$ \\
\hline $2007 / 2008$ & 17 & 6 & 3 & $85.71 \%$ & $42.85 \%$ & $50 \%$ \\
\hline $2008 / 2009$ & 14 & 9 & 7 & $64.28 \%$ & $50 \%$ & $77 \%$ \\
\hline $2009 / 2010$ & 21 & 20 & 19 & $95.23 \%$ & $90.47 \%$ & $95 \%$ \\
\hline $2010 / 2011$ & 11 & 10 & 10 & $90.90 \%$ & $90.90 \%$ & $100 \%$ \\
\hline $2011 / 2012$ & 12 & 12 & 12 & $100 \%$ & $100 \%$ & $100 \%$ \\
\hline
\end{tabular}

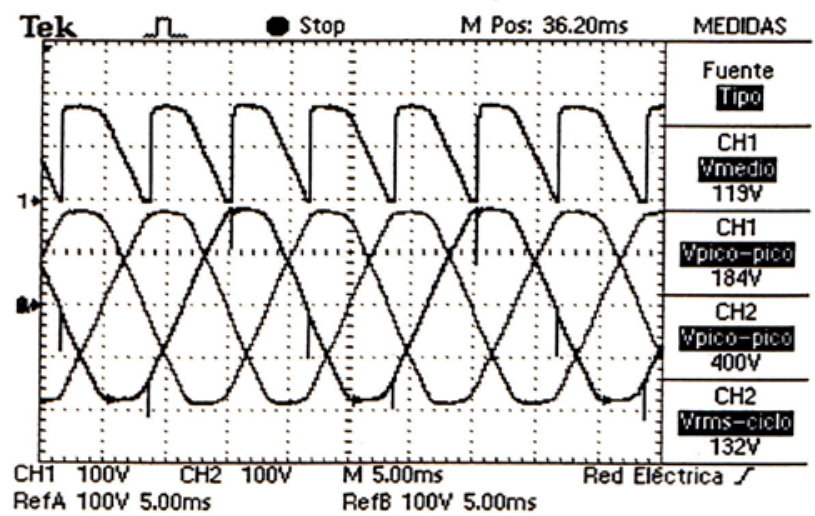

(a)

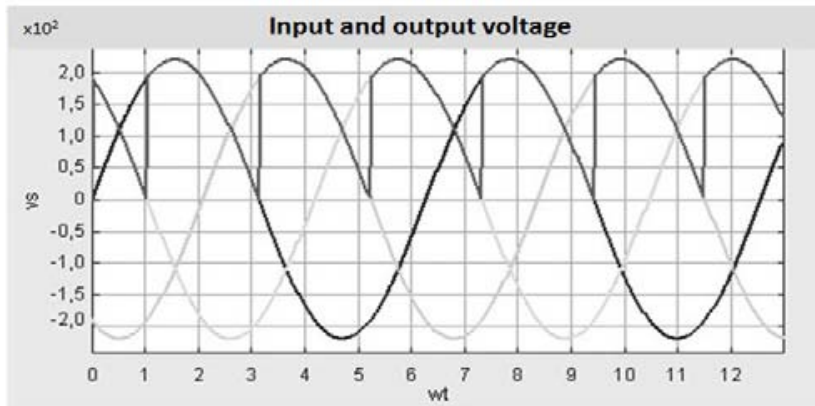

(b)

Fig. 12. Comparison between: (a) experimental results and (b) simulation result for an ac-dc three-phase controlled converter in a half-bridge topology and $R L$ load.

P/R, P/D (D: done, R: registered, P: passed).

It can be observed that due to the increase in the use of more tools for the comprehension of power electronics, the ratio $\mathrm{P} / \mathrm{D}$ has been increased considerably and, in general, results have been thoroughly satisfactory. It is worthy to note that each year brought an increase in overall results.

Regarding the satisfaction surveys, students consider the interactive tools both useful and positive and in particular, the simulations in Java. These results emerge from the test performed relative to the methodology and educational package for the power electronics teaching/learning and from the interviews with the students. The evaluated items are:

1) Aid in the study of power electronics subject.

2) Facility of concept searching.

3) Interactivity.

4) Improvement of the obtained results.

5) Global score.

The results are shown in Fig. 13. The answers are numerical, where the values " 5 " and " 1 " correspond, respectively, to maximum and minimum grades.

\section{CONCLUSIONS}

In this paper, an educational computer-aided platform for power electronics teaching purpose has been presented. The results of its application, in conjunction with traditional teaching techniques, in a first course of power electronics 


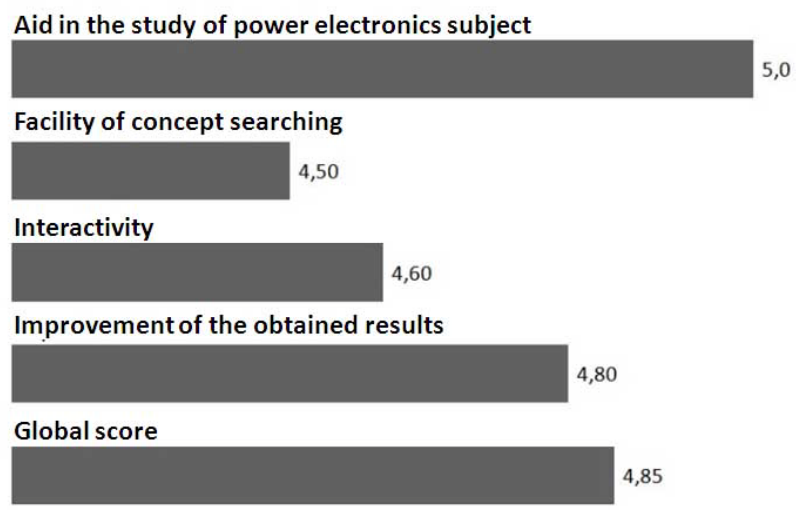

Fig. 13. Evaluation results.

called "Power Electronics System” are shown in Table I.

The main advantages of this platform are:

- It can be employed as a teaching aid in any general course of power electronics, because the contents are similar in many universities.

- It combines in a single platform all tools needed for a power electronics course: e-book, power electronics animations, Java simulations and laboratory tutorial.

- It is freely available on Internet and accessible to any person interested in power electronics.

- It is interactive and increases students' autonomy.

- The results in the mark statistics show that the ratio passed/done has increased considerably.

Future developments include the translation of the platform into other languages and the creation of new animations switched power converters.

\section{REFERENCES}

[1] K. C. Kong Tse, Complex behaviour of switching power converters, CRC Press, 2005.

[2] C. Mi, J. Shen and T. Ceccarelli, "Continuing education in power electronics,” IEEE Trans. Educ., Vol. 48, pp. 183-190, Feb. 2005.

[3] M. Trivedi, E. A. McShane, R. Vijayalakshmi, and A. Mulay, "An improve approach to application-specific power electronics education-switch characterization and modeling," IEEE Trans. Educ., Vol. 45, pp. 57-64, Feb. 2002.

[4] F. Jurado and M. Valverde, "Applications of signal processing tools in a power systems course,” Int. Journal of Electrical Engineering Education, pp. 28-42, Jan. 2004.

[5] N. Mohan, "A novel approach to integrate computer exercises into teaching of utility-related applications of power electronics," IEEE Trans. Power Syst., Vol. 7, pp. 359-362, Feb. 1992.

[6] N. Mohan, P. Robbins, P. Imbertson, T. M. Underland, R. C. Panaitescu, A. K. Jain, P. Jose, and T. Begalke, "Restructuring of first courses in power electronics and electric drives that integrates digital control," IEEE Trans. Power Electron., Vol. 9, pp. 250-255, May 1994.

[7] N. Mohan, A. K. Jain, P. Jose, and R. Ayyanar, "Teaching utility applications of power electronics in a first course on power systems," IEEE Trans. Power Syst., Vol. 19, pp. 40-47, Feb. 2004
[8] N. Mohan, T. M. Undeland, and W. P. Robbins, Power electronics: converters, applications and design, John Wiley \& Sons Inc., 2003.

[9] M. H. Rashid, Power electronics handbook, Elsevier, 2011.

[10] J. G. Kassakian, M. F. Schlecht, and G. C. Vergese, Principles of power electronics, Addison-Wesley, 1991.

[11] D. Hart, Introduction to power electronics, Prentice-Hall, 1997.

[12] B. K. Bose, Modern power Electronics and AC drives, Prentice-Hall, 2001.

[13] J. E. Tate, T. J. Overbye, J. Sebestik, and G. C. Reese, "Interactive lessons for pre-university power education," IEEE Trans. Power Syst., Vol. 23, pp. 824-830, Aug. 2008.

[14] S. Surynarayanan and E. Kyriakides, "An online portal form collaborative learning and teaching for power engineering education,” IEEE Trans. Power Syst., Vol. 19, pp. 73-80, Feb. 2004.

[15] J. M. Jiménez-Martínez, F. Soto, E. de Jódar, and J. A. Villarejo, "A new approach for teaching power electronics converter experiments,” IEEE Trans. Educ., Vol. 48, pp. 513-519, Aug. 2005.

[16] N. Mohan, W. P. Robbins, T. M. Underland, R. Nilssen, and O. Mo, "Simulation of power electronic and motion control systems-An overview,” Proc. of the IEEE, Vol. 82, pp. 1287-1302, Aug. 1994.

[17] L. Max, T. Thiringer, T. Underland, and R. Karlsson, "Power electronics design laboratory exercise for final-year M. Sc. Students,” IEEE Trans. Educ., Vol. 52, pp. 524-531, Nov. 2009.

[18] D. A. Torrey, “A project-oriented power electronics laboratories,” IEEE Trans. Educ., Vol. 52, pp. 524-531, Nov. 2009.

[19] C. Elmas and Y. Sönmez, "An educational tool for power electronics circuits," Computer Applications in Engineering Education, Vol. 18, pp. 157-165, March 2010.

[20] J. E. Stephenson, C. Brown, and D. K. Griffin, "Electronic delivery of lectures in the university environment: an empirical comparison of three delivery styles," Computers \& Education, Vol. 50, pp. 640-651, Apr. 2008.

[21] D. Lascu, P. Bauer, M. Babaita, M. Lascu, V. Popescu, A. Popovici, and D. Negoitescu, "Distance education in soft-switching inverters,” Journal of Power Electronics, Vol. 10, pp. 628-634, Nov. 2010.

[22] N. Ertugrul, "Interactive teaching and self-study tools for power electronics,” Journal of Power Electronics, Vol. 2, No. 4, pp. 258-267, Oct. 2002.

[23] A. Pozo-Ruz, F. D. Trujillo, M. A. Callejón, and J. García, "Plataforma virtual didáctica de Electrónica de Potencia acorde a los paradigmas de los ECTS," in Proc. 17 Congreso Universitario de Innovación Educativa en Enseñanzas Técnicas, 2009.

[24] A. Pozo-Ruz and F. D. Trujillo -Material de apoyo para el estudio de la Electrónica de Potencia: animaciones de los principales convertidores conmutados de potencia, University of Málaga (Spain)http://www.uma.es/investigadores/grupos/electronica_pote ncia/documents/tutoriales/web_convertidores_nuevo2/inde x.htm, Jun. 30th 2012.

[25] A. Pozo-Ruz and F. D. Trujillo, "A web-based tool for a power electronics course," in Proc. Conference International Promotion and Innovation with New Technologies in Engineering Education, pp. 161-166, 2011. 
[26] F. Esquembre, Creación de simulaciones interactivas en Java. Aplicación a la enseñanza de la Física, Prentice Hall, 2005.

[27] A. Pozo-Ruz, M. J Morón, F. D. Trujillo, and G. Torcello, "Plataforma virtual interactiva para la docencia del Laboratorio de Electrónica de Potencia," in Proc. XI Simposio Nacional de Tecnologías de la Información y las Comunicaciones en la Educación, pp. 59-62, 2010.

[28] M. Derr, and T. Symes, Joomla!, Peachpit Press, 2009.

[29] IIT Kharagpur -Course of Power Electronics in Electrical Engineering-http://nptel.iitm.ac.in/courses/Webcourse-con tents/IIT\%20Kharagpur/Power\%20Electronics/New_index 1.html, Jun. 30th 2012

[30] Massachusetts Institute of Technology -Free online course materials (OCW-MIT)- http://ocw.mit.edu/index.htm, Jun. 30th 2012.

[31] Universidad Carlos III de Madrid -Curso de electrónica de potencia-http://ocw.uc3m.es/tecnologia-electronica/electro nica-de-potencia, Jun. 30th 2012.

[32] C. G. Grover, Flash CS4: The missing manual, O’Reilly \& Associates, 2008.

[33] Powersim -PSIM: From design to simulation and implementation- http://www.powersimtech.com, Jun. 30th 2012.

[34] S. Chwirka -Power converter design using SABER simulator, Analogy Inc., Beaverton, Oregonhttp://www.dee.ufc.br/ rene/industrial/Capi05/forward_de sign.pdf, Sep. 15th 2011.

[35] M. Nuruzzaman, Modelling and simulation in simulink for engineers and scientists, Bloomington: Authorhouse, 2005.

[36] R. W. Goody, OrCAD PSpice para windowns (vol. I, II and III), Prentice Hall, 2002.

[37] U. Drofenik and J. W. Kolar, "A novel interactive power electronics seminar (iPES) developed at the Swiss Federal Institute of Technology (ETH) Zurich,” Journal of Power Electronics, Vol. 2, No. 4, pp. 250-257, Oct. 2002.

[38] Gecko Research -Power electronics simulationshttp://www.gecko-research.com, Sep. 15th 2011.

[39] C. A. Canesin, F. A. S. Goncalvez, and L. P. Sampaio, "Simulation tools for power electronics courses based on Java Technologies,” IEEE Trans. on Education, Vol. 53, pp. 580-586, Nov. 2010.

[40] W. Robbins, N. Mohan, C. Henze, and T. Undeland, “A building-block-based power electronics instructional laboratory," in Proc. Power Electronics Specialist Conference, pp. 467-472, 2002.

[41] R. M. Wolf, The nature of educational evaluation, The international encyclopedia of educational evaluation, Pergamon Press, 1990.

[42] Universidad de Málaga -ETS Ingeniería Industrialhttp://www.etsii.uma.es, Jun. 30th 2012.

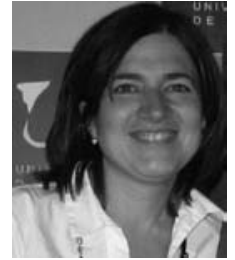

Ana Pozo Ruz received a B.S. degree (1995) and a Ph.D. degree (2001) in Industrial Engineering at the University of Malaga, Spain. Since 1997 she has been working at the University of Málaga. In 2002, she became an associate professor in the Electronic Technology Dep. of the University of Málaga. Her research field includes the use of new methods and technology in Power Electronics teaching and the development of new tools to convey knowledge.

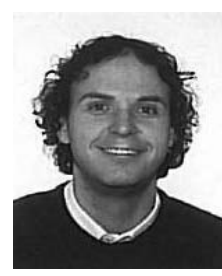

F. David Trujillo Aguilera received a B.S. degree (1997) in Telecommunication Engineering from University of Málaga and a $\mathrm{Ph}$. D. in Innovation in Engineering Education (2012). From then until 2002, he worked as assistant professor in the Electronic Technology Dep. of the University of Málaga and in December 2002, he became an associate professor in the same Department. His research interests cover the routing in ad hoc networks; the presence in virtual reality and the European Higher Education Area and its new involvement in the learning/teaching process.

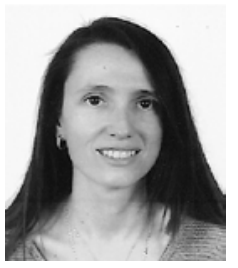

M. J. Morón (born in 1975) received the B.S. degree (2000) and the Ph.D. degree (2008) in Electrical (Telecommunications) Engineering. From July 2000 to 2004, she worked as a consultant in a telecommunications company. From October 2004 to now, she has worked as a research assistant and an assistant professor at Department of Electronic Technology and at Dep. of Computer Architecture. Her research area includes Bluetooth performance modeling, wireless technologies for Telemedicine applications and usability issues in Wireless Personal Area Networks.

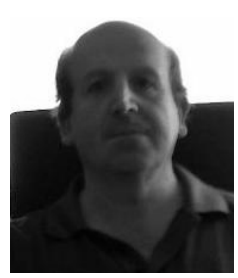

of Granada).
Ernesto Rivas received a B.S. degree (1985) in Industrial Technical Engineering and the B.S. degree (2005) in Electronic Engineering. He combines his duties as a laboratory assistant and practice coordinator in the Electronic Technology Dep. (University of Málaga) with research about Chemical Process Technology (Universisty 